\title{
Prosocial Effects of Nicotine and Ethanol in Adolescent Rats Through Partially Dissociable Neurobehavioral Mechanisms
}

\author{
Viviana Trezza', Petra JJ Baarendse' and Louk JMJ Vanderschuren*,' \\ 'Department of Neuroscience and Pharmacology, Rudolf Magnus Institute of Neuroscience, University Medical Center Utrecht, Utrecht, \\ The Netherlands
}

\begin{abstract}
The widespread use of tobacco and alcohol among adolescents might be related to the ability of nicotine and ethanol to facilitate social interactions. To investigate the neurobehavioral mechanisms underlying the prosocial effects of nicotine and ethanol, we focused on social play behavior, the most characteristic social activity in adolescent rats. Social play behavior is rewarding, and it is modulated through opioid, cannabinoid and dopaminergic neurotransmission, which are also involved in the reinforcing properties of nicotine and ethanol. We found that nicotine and ethanol increased social play, without affecting locomotion or social exploration. Their effects depended on the level of social activity of the partner, and were comparable in familiar and unfamiliar environments. At doses that increased social play, nicotine and ethanol had no anxiolytic effects in the elevated plus-maze. By contrast, the prototypical anxiolytic drug diazepam reduced social play at doses that reduced anxiety. The effects of nicotine on social play were blocked by the opioid receptor antagonist naloxone, the $C_{1}$ cannabinoid receptor antagonist SRI4I7I6A, and the dopamine receptor antagonist $\alpha$-flupenthixol. The effects of ethanol were blocked by SRI4I7I6A and $\alpha$-flupenthixol, but not by naloxone. Combined administration of subeffective doses of nicotine and ethanol only modestly enhanced social play. These results show that the facilitatory effects of nicotine and ethanol on social play are behaviorally specific and mediated through neurotransmitter systems involved in positive emotions and motivation, through partially dissociable mechanisms. Furthermore, the stimulating effects of nicotine and ethanol on social play behavior are independent of their anxiolytic-like properties.
\end{abstract}

Neuropsychopharmacology (2009) 34, 2560-2573; doi: I0.1038/npp.2009.85; published online 5 August 2009

Keywords: social behavior; adolescence; ethanol; nicotine; opioid

\section{INTRODUCTION}

Tobacco and alcohol, alone or in combination, are widely used by adolescents. The initial motivation to use these drugs is closely linked to the social context. At this age, peer pressure plays a crucial role in the initiation of smoking and drinking. In addition, it is a common belief that these drugs facilitate interaction with peers, peer acceptance, and group cohesion; in other words, meeting up with friends is more fun when cigarettes and alcohol are available. Studies in rodents have supported this notion, by showing that low doses of nicotine (Cheeta et al, 2001a,b) and ethanol (Varlinskaya et al, 2001; Varlinskaya and Spear, 2002, 2006) increase social behavior in adolescent and adult rats. However, the neurobehavioral mechanisms underlying nicotine- and ethanol-induced social facilitation are not completely understood. To address this issue, we investi-

\footnotetext{
*Correspondence: Dr LJMJ Vanderschuren, Department of Neuroscience and Pharmacology, Rudolf Magnus Institute of Neuroscience, University Medical Center Utrecht, Universiteitsweg 100, Utrecht 3584 CG, The Netherlands, Tel: + 3 I 88 75688II, Fax: + 3 I 887568 I55, E-mail: I.j.m.j.vanderschuren@umcutrecht.nl

Received 24 April 2009; revised 29 June 2009; accepted I July 2009
}

gated the effects of nicotine and ethanol on social play behavior in adolescent rats.

Social play behavior is the most vigorous form of social interaction displayed by adolescent mammals. It is strongly conserved in evolution and it is of major importance for social and cognitive development (Fagen, 1981; Vanderschuren et al, 1997; Špinka et al, 2001). For example, social isolation during adolescence, ie, depriving the animals of social play, induces several behavioral impairments in adulthood, particularly in the social domain (Potegal and Einon, 1989; Hol et al, 1999; van den Berg et al, 1999a, b). Consistent with its importance for development and survival, social play is rewarding in adolescent rats: it can be used as a positive incentive for maze learning (Humphreys and Einon, 1981; Normansell and Panksepp, 1990) and place conditioning (Calcagnetti and Schechter, 1992; Douglas et al, 2004; Thiel et al, 2008; Trezza et al, 2009).

Given its rewarding value, it is not surprising that social play is modulated through neural systems that also mediate the positive subjective and motivational properties of drugs of abuse. For example, we have recently shown that interacting opioid, cannabinoid, and dopaminergic neurotransmitter systems modulate social play behavior 
(Trezza and Vanderschuren, 2008a,b, 2009). Opioid, cannabinoid, and dopaminergic neurotransmission have been implicated in the reinforcing effects of nicotine and ethanol (Van Ree et al, 1999; Di Chiara, 2000; Picciotto and Corrigall, 2002; Weiss and Porrino, 2002; Laviolette and van der Kooy, 2004; Cohen et al, 2005; Maldonado et al, 2006; Pierce and Kumaresan, 2006; Markou, 2008). Therefore, we hypothesized that these neurotransmitter systems are also involved in the effects of nicotine and ethanol on social play behavior.

In humans, the anxiolytic-like properties of nicotine and ethanol have been implicated in tobacco and alcohol use. Thus, frequent users report that smoking and drinking reduce anxiety and relieve stress (Pomerleau, 1986; Gilbert et al, 1989; Kushner et al, 1990, 2000; Pomerleau and Pomerleau, 1990). Studies in rodents have yielded inconsistent results, because both anxiolytic and anxiogenic effects of nicotine and ethanol have been reported, depending on the dose, sex, species, strain, the behavioral test used, and, most importantly, the age of the animals (Cheeta et al, 2001a; Elliott et al, 2004; Varlinskaya and Spear, 2006). Nevertheless, the social facilitatory effects of nicotine and ethanol during adolescence may be the result of the anxiolytic effects of these drugs. To address this issue, we compared the effects of nicotine and ethanol on social play behavior in a familiar or unfamiliar environment, as selective increases of social behavior in unfamiliar environments indicate anxiolytic effects of drugs (File and Seth, 2003). We also investigated whether doses of nicotine and ethanol that increase social play behavior affect behavior in the elevated plus-maze, and compared these effects with those of the prototypical anxiolytic drug diazepam.

\section{MATERIALS AND METHODS}

\section{Animals}

Male Wistar rats (Charles River, Sulzfeld, Germany) arrived in our animal facility at 21 days of age and were housed in groups of four in $40 \times 26 \times 20 \mathrm{~cm}(\mathrm{l} \times \mathrm{w} \times \mathrm{h})$ Macrolon cages under controlled conditions (temperature $20-21^{\circ} \mathrm{C}, 55 \pm 15 \%$ relative humidity, and $12 / 12 \mathrm{~h}$ light cycle with lights on at 0700 hours). Food and water were available ad libitum. All animals were experimentally naive and were used only once (ie, different groups of rats were used for each experiment). All experiments were approved by the Animal Ethics Committee of Utrecht University and were conducted in agreement with Dutch laws (Wet op de Dierproeven, 1996) and European regulations (Guideline 86/609/EEC).

\section{Drugs}

Nicotine (Sigma-Aldrich, Schnelldorf, Germany) was dissolved in saline and administered subcutaneously (s.c.) $10 \mathrm{~min}$ before the test. Ethanol (Sigma-Aldrich) was administered intraperitoneally (i.p.) $1 \mathrm{~h}$ before the test, as a $12.6 \%(\mathrm{v} / \mathrm{v})$ solution in physiological saline. Ethanol doses were varied by changing the volume of the $12.6 \%$ ethanol solution. The $\mathrm{CB}_{1}$ cannabinoid receptor antagonist SR141716A (National Institute of Mental Health's Chemical Synthesis and Drug Supply Program, Bethesda, MD, USA) was dissolved in $5 \%$ Tween-80/5\% polyethylene glycol/ saline. The nicotinic receptor (nAchR) antagonist mecamylamine hydrochloride (Sigma-Aldrich), the opioid receptor antagonist naloxone (Tocris Cookson, Avonmouth, UK) and the dopamine receptor antagonist $\alpha$-flupenthixol (Sigma-Aldrich) were dissolved in saline. SR141716A (i.p.), naloxone (s.c.), mecamylamine (s.c.), and $\alpha$-flupenthixol (i.p.) were administered $30 \mathrm{~min}$ before ethanol and nicotine, respectively. Diazepam (from commercially available vials $(10 \mathrm{mg} / 2 \mathrm{ml})$ of Valium, Roche, Switzerland) was diluted to the final concentration with $5 \%$ Tween-80/5\% polyethylene glycol/saline, and administered i.p. $30 \mathrm{~min}$ before the test. As opioid, cannabinoid, and dopamine receptor antagonists have been shown to reduce social play, we used doses of naloxone, SR141716A, and $\alpha$-flupenthixol that had no effect on social play by themselves (Trezza and Vanderschuren, 2009). Except ethanol, solutions were administered in a volume of $2 \mathrm{ml} / \mathrm{kg}$. Because of the importance of the neck area in the expression of social play behavior (Pellis and Pellis, 1987), s.c. injections were administered in the flank.

\section{Procedures}

Social play behavior. All the experiments were performed in a sound attenuated chamber under dim light conditions. The testing arena consisted of a Plexiglas cage measuring $40 \times 40 \times 60 \mathrm{~cm}(1 \times \mathrm{w} \times \mathrm{h})$, with approximately $2 \mathrm{~cm}$ of wood shavings covering the floor. At 26-28 days of age, rats were individually habituated to the test cage for $10 \mathrm{~min}$ on each of the 2 days before testing. In the two experiments where the effects of nicotine and ethanol were tested in an unfamiliar environment, the animals were handled, but not habituated to the test cages on the 2 days before testing. On the test day, the animals were socially isolated for $3.5 \mathrm{~h}$ before testing, to enhance their social motivation and thus facilitate the expression of social play behavior during testing. This isolation period has been shown to induce a half-maximal increase in the amount of social play behavior (Niesink and Van Ree, 1989; Vanderschuren et al, 1995a,b 2008). At the appropriate time before testing, pairs of animals were treated with drugs or vehicle. In all experiments, except for two, both animals of a pair received the same drug treatment. The test consisted of placing two animals into the test cage for $15 \mathrm{~min}$. The animals in a pair did not differ more than $10 \mathrm{~g}$ in body weight and had no previous common social experience.

The behavior of the animals was videotaped and analysis from the video tape recordings was performed afterwards. Coding of the drug solutions ensured that both during the experiment and analysis of behavior, the experimenter was unaware of the treatment of the animals. Behavior was assessed per pair of animals, except in two experiments, where the behaviors of both members of a test pair were scored separately. For analysis of behavior the Observer 3.0 software (Noldus Information Technology BV, Wageningen, The Netherlands) was used.

In rats, a bout of social play behavior starts with one rat soliciting ('pouncing') another animal, by attempting to nose or rub the nape of its neck. The animal that is pounced upon can respond in different ways: if the animal fully rotates to its dorsal surface, 'pinning' is the result, ie, one animal lying with its dorsal surface on the floor with the 
other animal standing over it. From this position, the supine animal can easily initiate another play bout, by trying to gain access to the other animal's neck. Thus, during social play, pinning, which is considered to be the most obvious posture in social play behavior in rats, is not an endpoint, but rather functions as a releaser of a prolonged play bout. If the animal that is pounced upon responds by evading, the soliciting rat may start to chase it, thus making another attempt to launch a play bout (Panksepp et al, 1984; Pellis and Pellis, 1987; Vanderschuren et al, 1997). The following behaviors were scored every $15 \mathrm{~min}$ : frequency of pinning, frequency of pouncing, and time spent in social exploration, ie, sniffing any part of the body of the test partner, including the anogenital area. Pinning and pouncing are the most characteristic indices of playful social behavior (Panksepp et al, 1984), whereas social exploratory behavior is a measure of general social interest. In the experiments where both members of a test pair were scored separately, pinning or pouncing were scored when the subject pinned or pounced its partner. Furthermore, in these experiments play responsiveness was calculated as the probability of an animal of being pinned as a result of play solicitation (pouncing) by the test partner (Pellis and Pellis, 1990, 1991).

Locomotor activity. To assess whether the effects of ethanol, nicotine, and diazepam on social play were secondary to changes in locomotor activity, rats were tested, at 28-30 days of age, for horizontal locomotor activity in plastic cages $(50 \times 33 \times 40 \mathrm{~cm} ; 1 \times \mathrm{w} \times \mathrm{h})$ using a video tracking system (EthoVision; Noldus Information Technology BV), which determined the position of the animal five times per second. At the appropriate time before testing, rats were treated with drugs or vehicle and then individually transferred from the home cage to the test cage, where locomotor activity was monitored for $1 \mathrm{~h}$.

Elevated plus-maze. To investigate whether doses of nicotine, ethanol, and diazepam that affect social play also induce changes in anxiety-related behaviors, 28- to 30-dayold rats were tested in the elevated plus-maze. The elevated plus-maze apparatus consisted of two open arms $(50 \times 10 \times$ $0 \mathrm{~cm})$ and two closed arms $(50 \times 10 \times 40 \mathrm{~cm})$ that extended from a common central platform $(10 \times 10 \mathrm{~cm})$. The apparatus, made of gray Plexiglas, was elevated to a height of $60 \mathrm{~cm}$ above the floor. A video camera above the maze was connected to a video recorder and a television monitor was connected to the video recorder.

The elevated plus-maze test (Pellow and File, 1986) was performed as follows. At the appropriate time before testing, rats were treated with drugs or vehicle and then individually placed on the central platform facing a closed arm, and a 5-min test period was recorded on videotape for subsequent analysis. Behavioral analyses were carried out using the Observer 3.0 software (Noldus Information Technology BV). The following parameters were analyzed:

(1) \% time spent on the open arms (\% TO): (seconds spent on the open arms of the maze/300) $\times 100$;

(2) \% open arm entries (\% OE): (the number of entries into the open arms of the maze/ number of entries into open + closed arms $) \times 100$;
(3) number of exploratory head dips (HDIPS) made over the edge of the open arms;

(4) number of stretched-attend postures (SAP) made from the exit of a closed towards an open arm. This exploratory posture is a forward elongation of the body, with static hind quarters, followed by a retraction to the original position.

\section{Statistical Analysis}

All data were expressed as mean \pm SEM. To assess the effects of single or combined treatments on social play behavior, data were analyzed using one-way or two-way ANOVA, respectively. In the experiments where the two rats in a couple received different treatments, the behaviors of the individual animals were analyzed using two-way ANOVA, with treatment of the test animal and treatment of the partner as factors. To assess the effects of ethanol and nicotine on social play behavior in a familiar or an unfamiliar test cage, data were analyzed using two-way ANOVA, with treatment and familiarity to the test cage as factors. To assess whether the effects of ethanol and nicotine changed over time in animals tested in a familiar or unfamiliar environment, the $15 \mathrm{~min}$ session was divided in three blocks of $5 \mathrm{~min}$, which were analyzed using two-way ANOVA for repeated measures. Parameters measured in the elevated plus-maze were analyzed using one-way ANOVA. Horizontal locomotor activity data were divided in four blocks of $15 \mathrm{~min}$, which were analyzed using one-way ANOVA for repeated measures. ANOVAs were followed by Tukey's post hoc test, where appropriate.

\section{RESULTS}

\section{Effects of Nicotine on Social Play Behavior}

Nicotine increased the most characteristic parameters of social play behavior. At a dose of $0.1 \mathrm{mg} / \mathrm{kg}$, it increased pinning (Figure 1a) and pouncing (Figure 1b). In contrast, nicotine did not alter social exploratory behavior (Figure 1c). To investigate whether nicotine affected the initiation to play, the responsiveness to play solicitation, or both, we performed an experiment in which none, one, or both members of a test pair were treated with nicotine. When behavior in this experiment was assessed per pair of animals, nicotine increased pinning (Figure 2a) only when both rats in a pair were treated. In contrast, nicotine increased pouncing when either one or both rats of a pair were treated (Figure $2 \mathrm{~b}$ ). This result was confirmed when behavior of individual members of a test pair was scored separately. Pinning was increased only in nicotine-treated rats interacting with nicotine-treated partners (Figure 2c). Pouncing was increased in all nicotine-treated rats, irrespective of the treatment of the partner (Figure 2d). However, nicotine had only an indirect effect on responsiveness to play solicitation, as vehicle-treated rats interacting with a nicotine-treated animal showed reduced play responsiveness (Figure 2e). Next, we compared the effects of nicotine on social play in rats tested in a familiar or in an unfamiliar environment, to assess whether familiarity to the test cage modulates the effects of nicotine on social play 

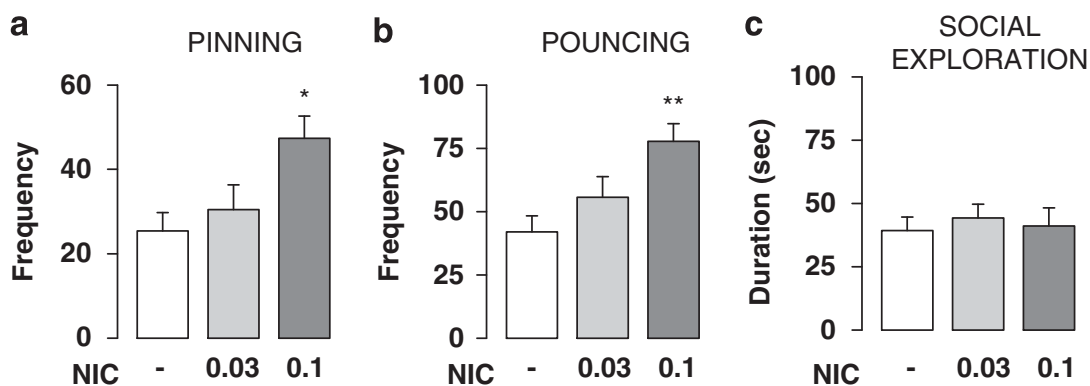

Figure I Nicotine (NIC, 0.03-0.I mg/ $/ \mathrm{kg}$, s.c.) increased pinning $\left((\mathbf{a}) F_{2,29}=4.45, p<0.05\right)$ and pouncing $\left((\mathbf{b}) F_{2,29}=5.72\right.$, p $\left.<0.0 \mathrm{I}\right)$, without affecting social exploration $\left((\mathbf{c}) F_{2,29}=0.19\right.$, n.s.). Data represent mean $\pm S E M$ frequency of pinning and pouncing, and mean \pm SEM duration of social exploration. ${ }^{*} p<0.05, * * * 0.01$ vs vehicle group (white bar; Tukey's post hoc test, $n=10-11$ per treatment group).

behavior. The effects of nicotine on pinning (Figure 3a) and pouncing (Figure $3 \mathrm{~b}$ ) were comparable in rats tested in a familiar or in an unfamiliar test cage. When behaviors were analyzed in $5 \mathrm{~min}$ intervals, nicotine increased pinning (Figure 3c) and pouncing (Figure 3d) during the first $5 \mathrm{~min}$ of the test, both in a familiar and in an unfamiliar test cage. This effect might be the result of the rapid pharmacokinetic profile of nicotine in rats, where brain levels of nicotine peak within approximately $15 \mathrm{~min}$ following subcutaneous injection (Matta et al, 2007).

\section{Effects of Ethanol on Social Play Behavior}

Ethanol increased social play behavior. At a dose of $0.25 \mathrm{~g} /$ $\mathrm{kg}$, ethanol increased pinning (Figure $4 \mathrm{a}$ ) and pouncing (Figure $4 \mathrm{~b}$ ), without affecting social exploration (Figure 4c). By treating either one or both partners of the test dyad, we next investigated whether ethanol affected play initiation, responsiveness to play solicitation, or both. When behavior was assessed per pair of animals, ethanol increased pinning (Figure 5a) and pouncing (Figure 5b) only when both rats in a pair were treated. The analysis of individual animals in each pair confirmed that pinning was increased only when both rats in a pair were treated with ethanol (Figure 5c). In contrast, pouncing was increased in ethanol-treated rats playing with either ethanol- or vehicle-treated partners (Figure 5d). However, ethanol did not affect responsiveness to play solicitation (Figure 5e). Familiarity to the test cage did not influence the effects of ethanol on pinning (Figure 6a), but it did influence the effects of ethanol on pouncing, as ethanol increased pouncing only in rats that were not habituated to the test cage before testing (Figure 6b). When behaviors were analyzed in $5 \mathrm{~min}$ intervals, pinning (Figure 6c) and pouncing (Figure 6d) did not differ between ethanol- and vehicle-treated rats during any of the 5 min blocks.

\section{Effects of Combined Exposure to Nicotine and Ethanol on Social Play Behavior}

Functional interactions exist between nicotine and ethanol in the regulation of motivational and emotional processes (Abreu-Villaca et al, 2008). These interactions have been suggested to play an important role in the combined use of tobacco and alcohol. Therefore, we investigated whether nicotine and ethanol also interact in the modulation of social play behavior in adolescent rats. Combined treatment with subeffective doses of nicotine $(0.03 \mathrm{mg} / \mathrm{kg})$ and ethanol $(0.125 \mathrm{~g} / \mathrm{kg})$ did not alter pinning (Figure $7 \mathrm{a})$, but resulted in a small but significant increase in pouncing (Figure $7 b$ ).

\section{Pharmacological Mechanisms of the Effects of Nicotine on Social Play Behavior}

At a dose that did not affect social play behavior by itself, the nAchR antagonist mecamylamine $(1 \mathrm{mg} / \mathrm{kg}$, s.c.) blocked the increase in pinning (Figure 8a) and pouncing (Figure $8 \mathrm{~b})$ induced by nicotine $(0.1 \mathrm{mg} / \mathrm{kg}$, s.c.), suggesting that the increase in social play induced by nicotine was mediated by activation of nAchRs. The opioid receptor antagonist naloxone $(1 \mathrm{mg} / \mathrm{kg}$, s.c.) blocked the increase in pinning (Figure 8c) and pouncing (Figure 8d) induced by nicotine $(0.1 \mathrm{mg} / \mathrm{kg}$, s.c.). Similarly, the effects of nicotine on pinning (Figure 8e and g) and pouncing (Figure $8 \mathrm{f}$ and h) were blocked by the $\mathrm{CB}_{1}$ cannabinoid receptor antagonist SR141716A $(0.1 \mathrm{mg} / \mathrm{kg}$, i.p.) and the dopamine receptor antagonist $\alpha$-flupenthixol $(0.125 \mathrm{mg} / \mathrm{kg}$, i.p.), respectively. These results suggest that opioid, cannabinoid, and dopaminergic neurotransmission are involved in the effects of nicotine on social play behavior.

\section{Pharmacological Mechanisms of the Effects of Ethanol on Social Play Behavior}

The opioid receptor antagonist naloxone $(1 \mathrm{mg} / \mathrm{kg}$, s.c.) did not block the increase in pinning (Figure $9 \mathrm{a}$ ) and pouncing (Figure $9 \mathrm{~b})$ induced by ethanol $(0.25 \mathrm{~g} / \mathrm{kg}$, s.c.), suggesting that the endogenous opioid system is not involved in the effects of ethanol on social play. In contrast, the $\mathrm{CB}_{1}$ cannabinoid receptor antagonist SR141716A $(0.1 \mathrm{mg} / \mathrm{kg}$, i.p.) and the dopamine receptor antagonist $\alpha$-flupenthixol $(0.125 \mathrm{mg} / \mathrm{kg}$, i.p.) completely antagonized the increase in pinning (Figure $9 \mathrm{c}$ and $\mathrm{e}$ ) and pouncing (Figure $9 \mathrm{~d}$ and $\mathrm{f}$ ) induced by ethanol $(0.25 \mathrm{~g} / \mathrm{kg}$, i.p.). These results show that both cannabinoid and dopaminergic mechanisms underlie the increase in social play induced by ethanol. The nAchR antagonist mecamylamine $(0.1 \mathrm{mg} / \mathrm{kg}$, s.c.) did not block the increase in pinning (Figure 9g) and pouncing (Figure 9h) induced by ethanol, suggesting that nAchRs are not involved in the increase in social play induced by ethanol. 

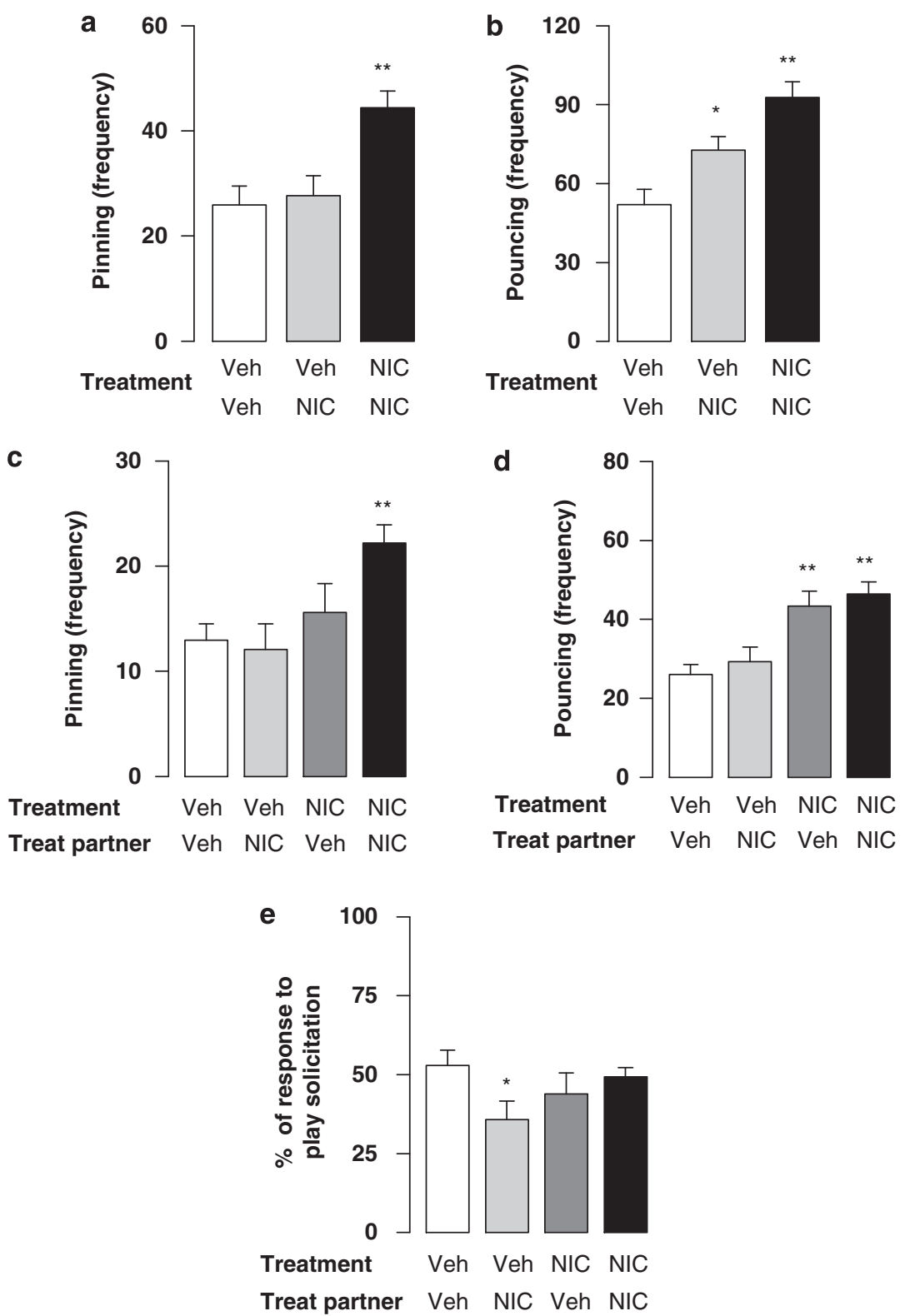

Figure 2 Effects of nicotine (NIC, $0.1 \mathrm{mg} / \mathrm{kg}$, s.c.) on social play behavior when injected to none, one, or both partners of the test dyad. When behavior was assessed per pair of animals $(\mathbf{a}, \mathbf{b})$, nicotine increased pinning $\left((\mathbf{a}) F_{229}=8.36, p=0.00 \mathrm{I}\right)$ only when both rats in a pair were treated. Conversely, nicotine increased pouncing when either one or both rats of a pair were treated $\left(\mathbf{( b )} F_{2,29}=13.12, p<0.00 I\right)$. This result was confirmed when behavior of individual members of a test pair was scored separately. Pinning was increased $\left((\mathbf{c}) F_{\text {(treatment subject)1.56 }}=9.22, p<0.01\right.$; $F_{\text {(treatment partner) } 1.56}=1.87$, n.s.;

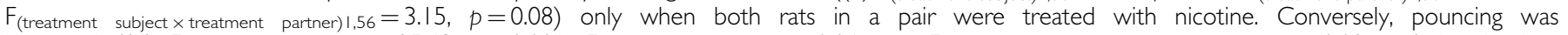
increased $\left((\mathbf{d}) \mathrm{F}_{\text {(treatment subject)1.56 }}=25.69, p<0.00\right.$ I; $F_{\text {(treatment partner) 1.56 }}=0.86$, n.s.; $F_{\text {(treatment subject } \times \text { treatment partner) 1.56 }}=0.02$, n.s.) in nicotinetreated rats interacting either with nicotine- or vehicle-treated partners. In couples where one rat was treated with nicotine and the other one with vehicle, vehicle-treated rats were less responsive to play solicitation $\left((\mathbf{e}) F_{\text {(treatment subject) 1.56 }}=0.00\right.$ I, n.s.; $F_{\text {(treatment partner) I.56 }}=0.59$, n.s.;

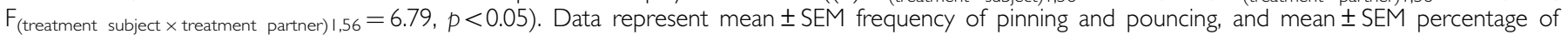
responses to play solicitation. $* 0<0.05,{ }^{*} * 0<0.0$ vs couples in which both rats were treated with vehicle (white bar; Tukey's post hoc test, $n=12-24$ per treatment group)

\section{Effects of Diazepam on Social Play Behavior}

The anxiolytic drug diazepam decreased social play behavior. At the dose of $1 \mathrm{mg} / \mathrm{kg}$, diazepam reduced pinning (Figure 10a) and pouncing (Figure 10b). This effect was behaviorally specific, because diazepam increased social exploration: compared to vehicle-treated rats, rats treated with $1 \mathrm{mg} / \mathrm{kg}$ diazepam spent more time on social exploration with their partner (Figure 10c).

\section{Effects of Nicotine, Ethanol, and Diazepam in the Elevated Plus-Maze}

Diazepam $(1 \mathrm{mg} / \mathrm{kg}$, i.p.) induced anxiolytic-like effects in adolescent rats tested in the elevated plus-maze. It increased the percentage of time spent in the open arms of the maze (Figure 11a) and the percentage of entries into the open arms (Figure 11b). Moreover, it increased the number of head dips (Figure 11c) and reduced the frequency of 
a
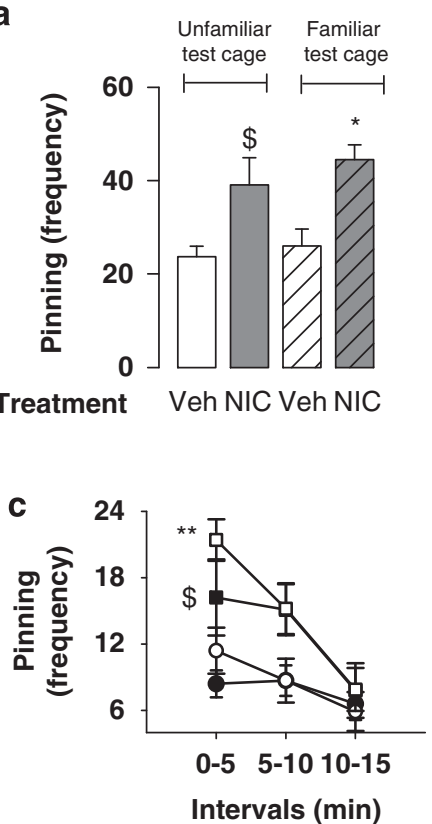

b

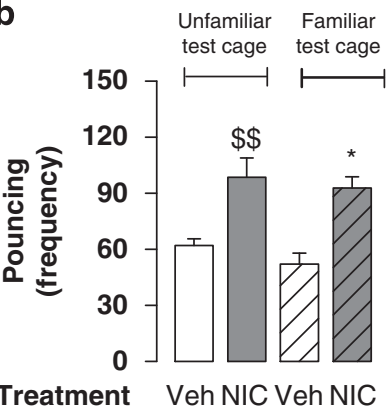

Figure 3 Effects of nicotine ( $\mathrm{NIC}, 0.1 \mathrm{mg} / \mathrm{kg}$, s.c.) on social play behavior in adolescent rats tested in a familiar or an unfamiliar environment. The effects of

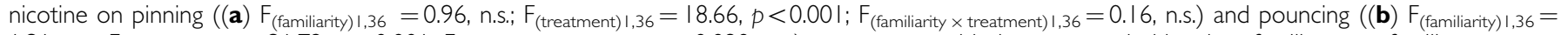

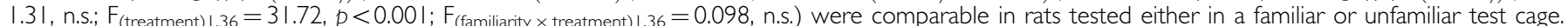
When behaviors were analyzed in $5 \mathrm{~min}$ intervals, nicotine increased pinning $\left((\mathbf{c}) F_{(\text {familiarity) } 1,36}=1.48, \quad\right.$ n.s.; $F_{\text {(treatment) I,36 }}=3.42, \quad p<0.05$; $F_{\text {(familiarity } \times \text { treatment) I.36 }}=0.07$ I, n.s.) and pouncing $\left((\mathbf{d}) F_{\text {(familiarity) I.36 }}=1 . \mid 4\right.$, n.s.; $F_{\text {(treatment) } 1.36}=7.76, p<0.00 I$; $F_{\text {(familiarity } \times \text { treatment) I.36 }}=0.86$, n.s.) during the first 5 min of the test, either in a familiar or unfamiliar test cage. Data represent mean \pm SEM frequency of pinning and pouncing. $* p<0.05$, *** $<0.0$ I vs vehicle-treated rats tested in a familiar test cage (striped white bar); ${ }^{\$} p<0.05,{ }^{\$ \$} p<0.01$ vs vehicle-treated rats tested in an unfamiliar test cage (white bar; Tukey's post hoc test, $n=10$ per treatment group).

a

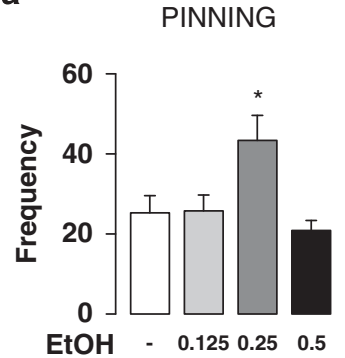

b

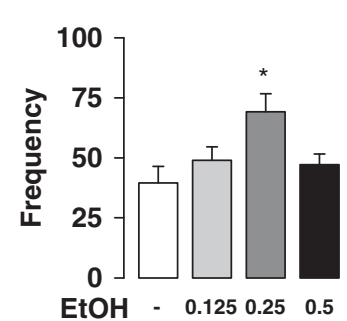

C SOCIAL EXPLORATION

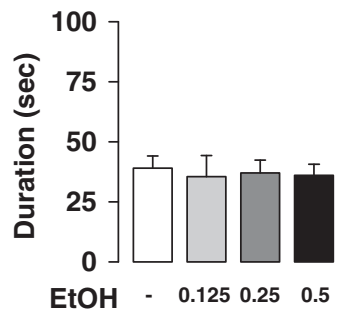

Figure 4 Ethanol (EtOH, 0.125-0.5 g/kg, i.p.) increased pinning $\left((\mathbf{a}) F_{3,29}=4.86, p<0.01\right)$ and pouncing $\left((\mathbf{b}) F_{3,29}=4.16, p<0.05\right)$ without affecting social exploration $\left((\mathbf{c}) \mathrm{F}_{3,29}=0.06\right.$, n.s.). Data represent mean $\pm \mathrm{SEM}$ frequency of pinning and pouncing, and mean $\pm \mathrm{SEM}$ duration of social exploration. *p $<0.05$ vs vehicle group (white bar; Tukey's post hoc test, $n=8$ per treatment group).

stretched-attend postures (Figure 11d). None of these parameters was affected by nicotine $(0.1 \mathrm{mg} / \mathrm{kg}$, s.c. $)$ and ethanol $(0.25 \mathrm{~g} / \mathrm{kg}$, i.p. $)$ treatment. This suggests that the increase in social play induced by nicotine and ethanol is not associated with changes in anxiety-like behaviors. Conversely, the decrease in social play induced by diazepam is not due to anxiogenic effects of this drug.

\section{Effects of Nicotine, Ethanol, and Diazepam on Locomotor Activity}

Nicotine $(0.1 \mathrm{mg} / \mathrm{kg}$, s.c.), ethanol (0.25 g/kg, i.p.) and diazepam $(1 \mathrm{mg} / \mathrm{kg}$, i.p. $)$ did not affect locomotor activity during any of the $15 \mathrm{~min}$ intervals of the test (Figure 12).

\section{DISCUSSION}

By focusing on social play behavior, the most characteristic social activity displayed by adolescent mammals, this study investigated the neurobehavioral mechanisms underlying the prosocial effects of nicotine and ethanol during adolescence. We found that a low dose of nicotine increased social play behavior in adolescent rats. In keeping with previous findings (Varlinskaya et al, 2001; Varlinskaya and Spear, 2002, 2006), a low dose of ethanol also increased social play behavior. The stimulating effects of nicotine and ethanol on social play were behaviorally specific. They were the result of increased play solicitation, but not associated with changes in social exploratory behavior, locomotor 

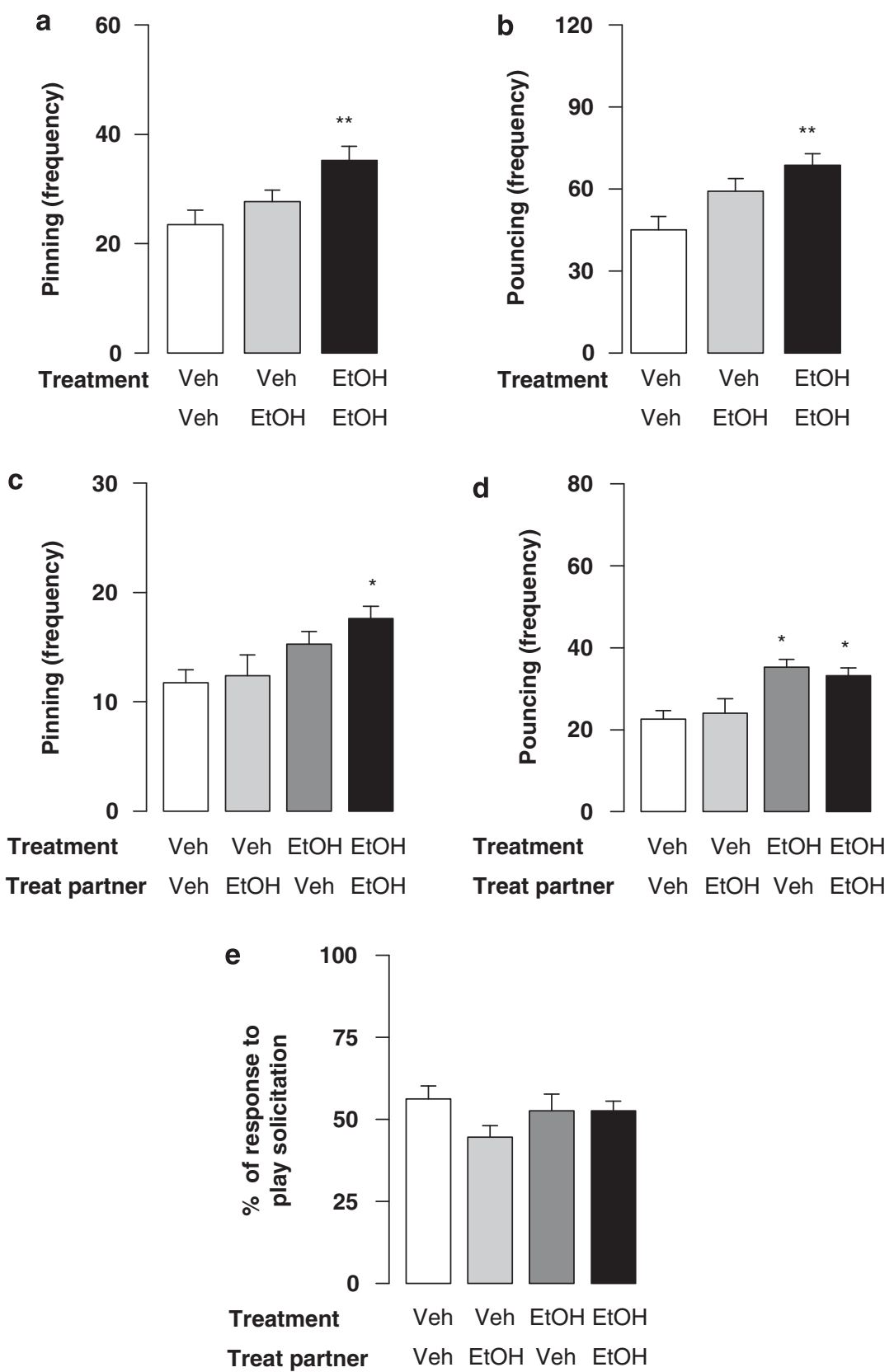

Figure 5 Effects of ethanol (EtOH, $0.25 \mathrm{~g} / \mathrm{kg}$, i.p.) on social play behavior when injected to none, one, or both partners of the test dyad. When behavior was assessed per pair of animals $(\mathbf{a}, \mathbf{b})$, ethanol increased pinning $\left((\mathbf{a}) F_{2,45}=6.07, p<0.0 \mathrm{I}\right)$ and pouncing $\left((\mathbf{b}) F_{2,45}=6.8 \mathrm{I}, p<0.0 \mathrm{I}\right)$ only when both rats in a pair were treated. The analysis of individual animals in a pair confirmed that pinning was increased only when both rats in a pair were treated with ethanol

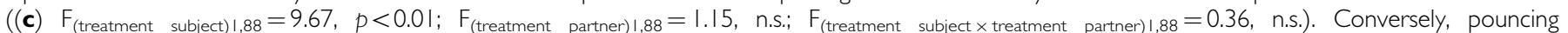

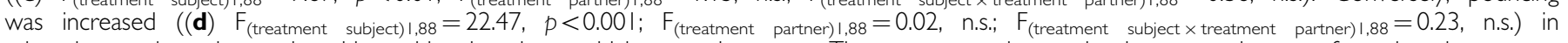
ethanol-treated rats interacting either with ethanol- or vehicle-treated partners. There were no changes in play responsiveness after ethanol treatment $\left((\mathbf{e}) F_{\text {(treatment subject) I,88 }}=0.29\right.$, n.s.; $F_{\text {(treatment partner) I,88 }}=2.06$, n.s.; $F_{\text {(treatment subject } \times \text { treatment partner) I,88 }}=2.03$, n.s.). Data represent mean $\pm S E M$ frequency of pinning and pouncing, and mean \pm SEM percentage of responses to play solicitation. $* p<0.05$, *** $p<0.0$ I vs couples in which both rats were treated with vehicle (white bar; Tukey's post hoc test, $n=|5-3|$ per treatment group).

activity, or anxiety-related behaviors. Nicotine enhanced social play behavior through interactions with dopamine, opioid, and cannabinoid neurotransmission, whereas the effects of ethanol were opioid-independent, but sensitive to blockade of dopamine or cannabinoid receptors. Combined administration of subeffective doses of nicotine and ethanol only modestly enhanced social play. These data demonstrate that nicotine and ethanol have selective prosocial effects, through pharmacological mechanisms that are at least partially dissociable.

When nicotine and ethanol were injected to none, one, or both partners of the test dyad, pouncing, which is an index of play solicitation, was found to be increased in all nicotine- and ethanol-treated rats, irrespective of the treatment of their test partners. Interestingly, pinning was significantly increased only when both rats in a pair were 
a

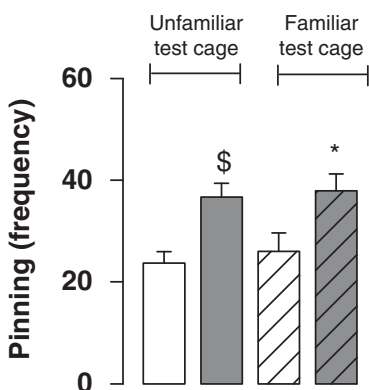

Treatment Veh EtOH Veh EtOH

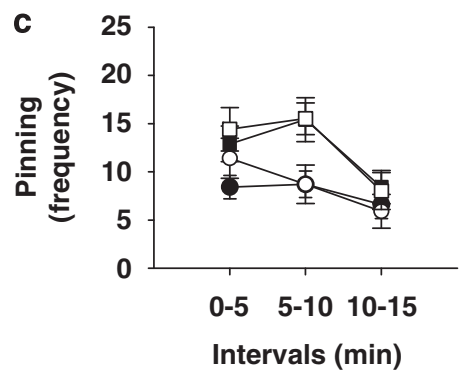

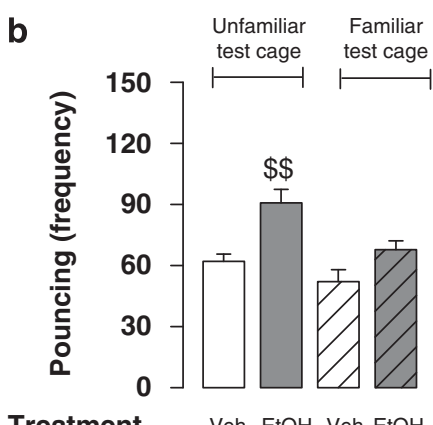

Treatment Veh $\mathrm{EtOH} \mathrm{Veh} \mathrm{EtOH}$

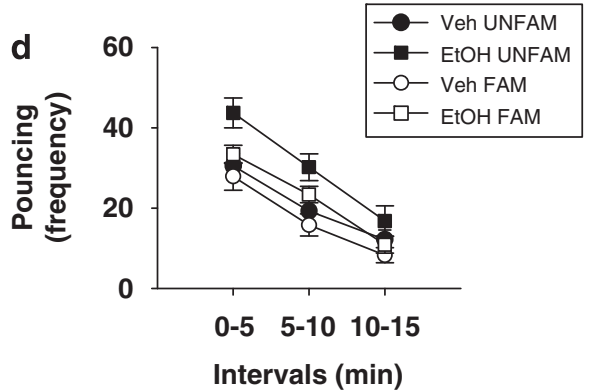

Figure 6 Effects of ethanol (EtOH, $0.25 \mathrm{~g} / \mathrm{kg}$, i.p.) on social play behavior in adolescent rats tested in a familiar or an unfamiliar environment. Ethanol increased pinning $\left((\mathbf{a}) \mathrm{F}_{\text {(familiarity) I,36 }}=0.33\right.$, n.s.; $F_{\text {(treatment) I,36 }}=16.9 \mathrm{I}, p<0.00 \mathrm{I}$; $F_{\text {(familiarity } \times \text { treatment) I.36 }}=0.033$, n.s.) in rats tested either in a familiar or in an unfamiliar test cage, whereas in increased pouncing $(\mathbf{b}) F_{\text {(familiarity) } 1,36}=9.8, p<0.01 ; F_{\text {(treatment) } 1,36}=\mid 7.74, p<0.001 ; F_{\text {(familiarity } \times \text { treatment) } I, 36}=$ I.52, n.s.) only in rats which were habituated to the test cage before testing. When behaviors were analyzed in 5 min intervals, pinning ((c) $F_{\text {(familiarity) } 1,36}=0.63$, n.s.; $F_{\text {(treatment) } 1,36}=1.7$, n.s.; $F_{\text {(familiarity } x \text { treatment) } 1,36}=0.07$ I, n.s.) and pouncing $\left((\mathbf{d}) F_{(\text {familiarity) } 1,36}=0.089\right.$, n.s.; $F_{\text {(treatment) } 1,36}=1.39$,

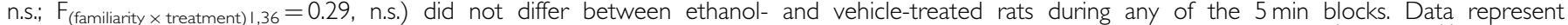
mean \pm SEM frequency of pinning and pouncing. ${ }^{*} p<0.05$ vs vehicle-treated rats tested in a familiar test cage (striped white bar); ${ }^{\$} p<0.05,{ }^{\$} p<0.0$ I vs vehicle-treated rats tested in an unfamiliar test cage (white bar; Tukey's post hoc test, $n=10$ per treatment group).
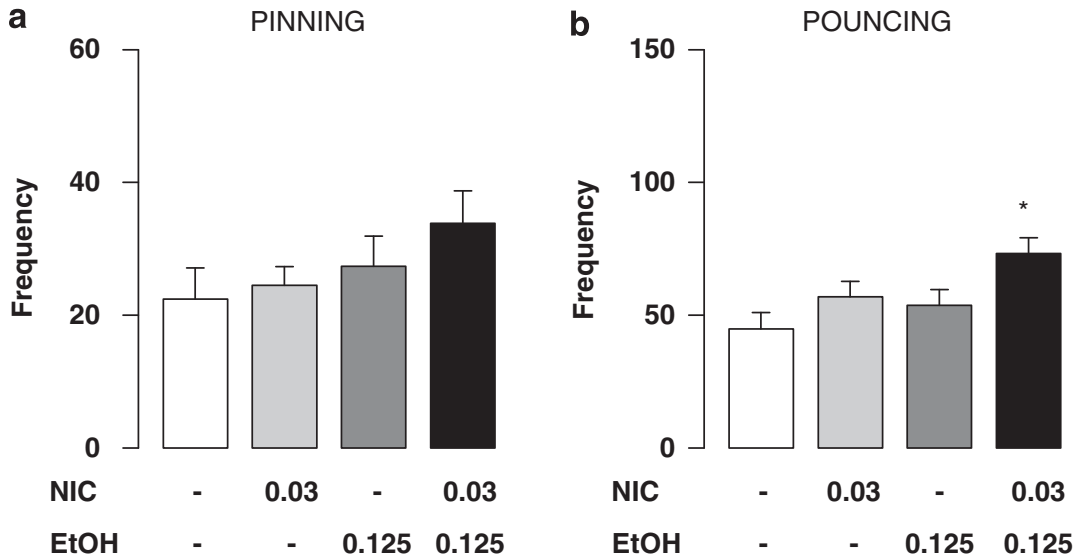

Figure 7 Combined treatment with subeffective doses of nicotine ( $\mathrm{NIC}, 0.03 \mathrm{mg} / \mathrm{kg}$, s.c.) and ethanol (EtOH, $0.125 \mathrm{~g} / \mathrm{kg}$, i.p.) induced no changes in pinning $\left((\mathbf{a}) F_{3,42}=1.36\right.$, n.s.), but resulted in a small, although significant increase in pouncing $\left((\mathbf{b}) F_{3,42}=4.24, p<0.05\right)$. Data represent mean $\pm S E M$ frequency of pinning and pouncing. ${ }^{*} p<0.05$ vs vehicle group (white bar; Tukey's post hoc test, $n=10-12$ per treatment group).

treated with nicotine or ethanol. Unlike pouncing, pinning requires active participation of both animals in the social interaction, indicating that the increase in social play induced by treatment with nicotine and ethanol depends on the level of social activity of the partners. In our experiments, rats responded to play solicitation by either evading (which in the vast majority of cases resulted in vigorous following and chasing, thus prolonging the playful interaction) or rotating to supine (resulting in pinning). Analysis of the likelihood of responding to pouncing by rotating to supine showed that nicotine and ethanol did not change this way of responding to play solicitation. It follows that nicotine and ethanol also hardly affected evasions. Thus, the increases in pinning found in dyads treated with nicotine or ethanol is likely to be the result of the increase in the number of pounces that occur in an interaction when both animals solicit their partners more.

In this study, we focused on the effects of nicotine and ethanol on social behavior in adolescent rats, because tobacco and alcohol use in adolescents might be related to 

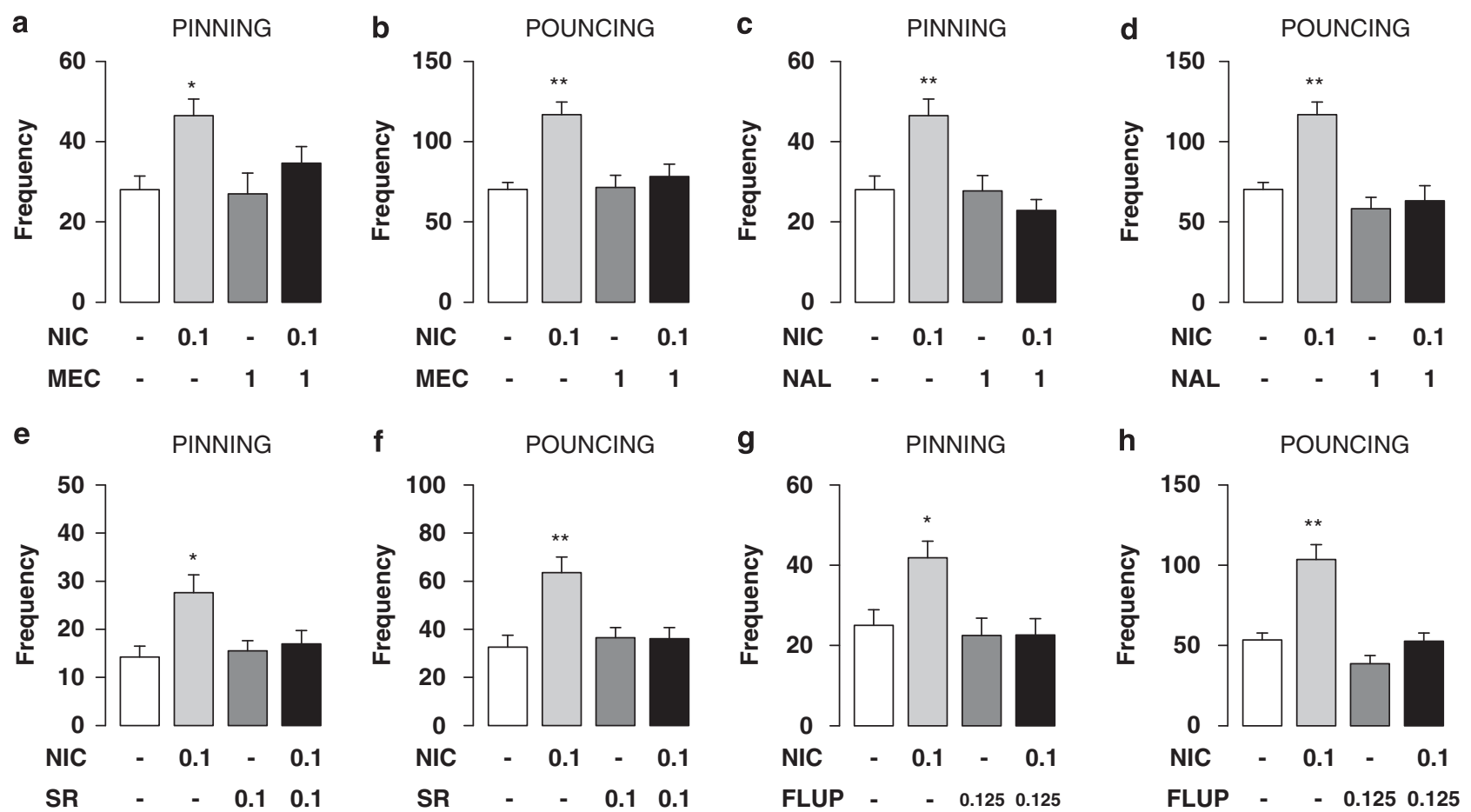

Figure 8 Pharmacological mechanisms of the effects of nicotine on social play behavior. The increase in pinning (a, $\mathbf{c}, \mathbf{e}, \mathbf{g})$ and pouncing (b, d, f, h) induced by nicotine (NIC, $0.1 \mathrm{mg} / \mathrm{kg}$, s.c.) was blocked by the nAChR antagonist mecamylamine (MEC, I mg/kg, s.c. $(\mathbf{a}) \mathrm{F}_{(\mathrm{MEC}) 1.27}=2.2, \mathrm{n} . \mathrm{s}$.; $\mathrm{F}_{(\mathrm{NIC}) 1.27}=9.04$,

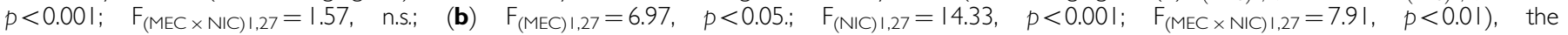
opioid receptor antagonist naloxone (NAL, I mg/kg, s.c.; (c) $\left.F_{(N A L) 1.26}=10.78, p<0.01 ; F_{(N I C) 1.26}=3.5, p=0.07 ; F_{(N A L} \times N \mid C\right) 1.26=10.33, p<0.001$; (d) $\left.F_{(N A L) I, 26}=29.8, p<0.00 I ; F_{(N I C) I, 26}=10.7, p<0.01 ; F_{(N A L \times N I C) I, 26}=13.45, p<0.01\right)$, the $C_{1}$ l cannabinoid receptor antagonist SRI4I7I6A

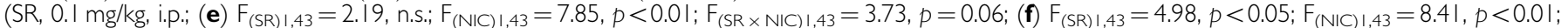
$\left.F_{(S R \times N I C) I, 43}=8.73, p<0.05\right)$, the dopamine receptor antagonist $\alpha$-flupenthixol (FLUP, $0.125 \mathrm{mg} / \mathrm{kg}$, i.p.; $(\mathbf{g}) F_{(F L U P) I, 27}=6.97, p<0.05 ; F_{(N I C) I, 27}=4.26$,

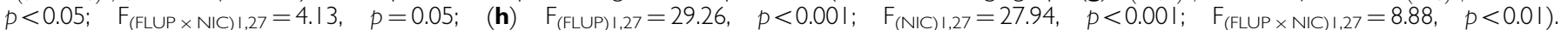
Data represent mean \pm SEM frequency of pinning and pouncing. $* p<0.05$, $* * *<0.01$ vs vehicle group (white bar; Tukey's post hoc test, $n=8-13$ per treatment group).

the prosocial effects of nicotine and ethanol. There is only limited information on whether the prosocial effects of nicotine and ethanol are specific for adolescent individuals. Nicotine has been found to stimulate social interaction in both adolescent and adult rats (Cheeta et al, 2001a, b), but playful social behaviors were not explicitly assessed in these studies. Varlinskaya and Spear $(2002,2006)$ have investigated the age-dependence of the effects of ethanol on social interaction. They found that the effects on playful social behavior were most pronounced in young adolescent animals (about the same age as the animals used in this study), but that the effects on social exploratory behavior were present from young adolescence until adulthood.

In the central nervous system, nicotine and ethanol exert their effects on behavior through different primary sites of action, but they interact with comparable neurotransmitter systems. The effects of nicotine are mediated by nAchRs, which are pentameric ligand-gated ion channels. Indeed, we found that pretreatment with mecamylamine, a nAchR antagonist that crosses the blood-brain barrier, blocked the effects of nicotine on pinning and pouncing, showing that the increase in social play induced by nicotine is mediated by activation of nAchRs. Ethanol modulates neuronal excitability through an interaction with a variety of ligandgated ion channels, including GABA-A receptors, NMDA glutamate receptors, and nAchRs (Tabakoff and Hoffman,
1996; Narahashi et al, 1999; Cardoso et al, 1999; Dopico and Lovinger, 2009). Investigating with which ion channel ethanol directly interacts to exert its effects on social play was beyond the scope of this study. However, our findings that pretreatment with mecamylamine did not alter the effect of ethanol on social play and that the effect of ethanol was not mimicked by diazepam, suggest that nAchRs and GABA-A receptors are not the primary mediators of this effect. Interestingly, low doses of the noncompetitive NMDA receptor antagonist MK-801 have been shown to enhance social play (Siviy et al, 1995), suggesting that the effect of ethanol on social play behavior is mediated through an interaction with NMDA receptors.

To investigate the pharmacological mechanisms underlying the increase in social play behavior induced by nicotine and ethanol, we focused on opioid, cannabinoid, and dopaminergic neurotransmission for the following reasons. These neurotransmitter systems play an important role in both drug and natural rewards (van Ree et al, 1999; Gardner, 2005; Salamone et al, 2005; Solinas and Goldberg, 2005; Maldonado et al, 2006; Pierce and Kumaresan, 2006; Berridge, 2007; Berridge and Kringelbach, 2008), and we have recently shown that they modulate social play behavior as well (Trezza and Vanderschuren, 2008a, b, 2009). In addition, opioid, cannabinoid, and dopamine systems have been implicated in the reinforcing properties of nicotine 
a

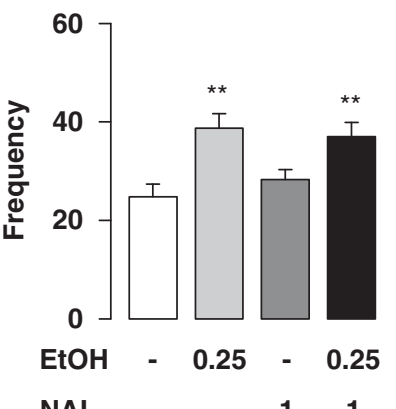

b

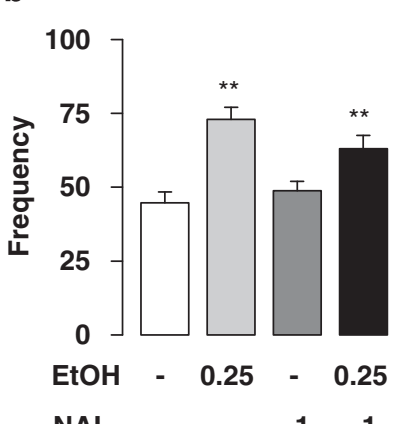

C

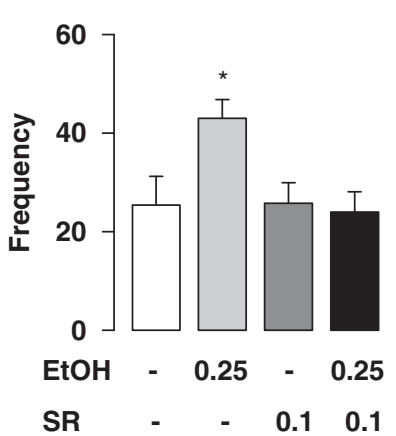

d POUNCING
NAL $\quad-\quad-\quad 1 \quad 1$

f

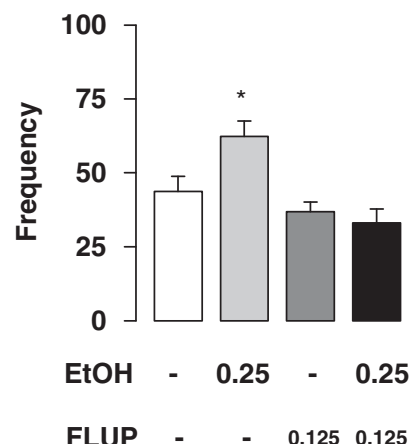

g

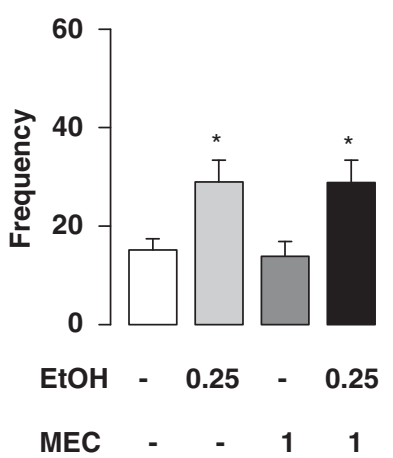

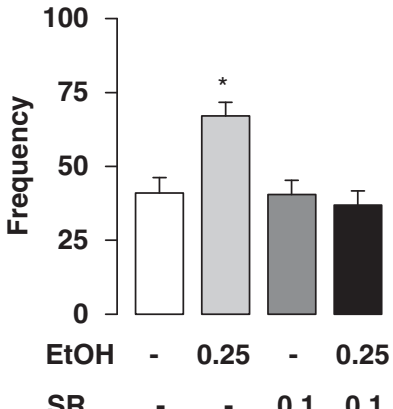

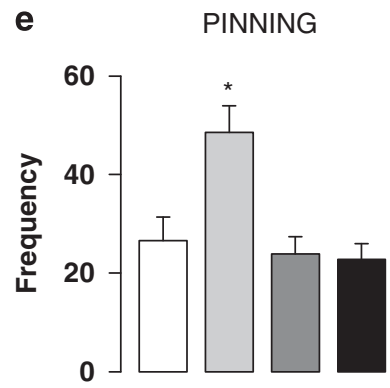

EtOH $\quad-0.25-0.25$

FLUP - $\quad-\quad 0.1250 .125$

Figure 9 Pharmacologial mechanisms of the effects of ethanol on social play behavior. The opioid receptor antagonist naloxone (NAL, I mg/kg, s.c.) did not block the increase in pinning $\left((\mathbf{a}) \mathrm{F}_{(\mathrm{NAL}) \mathrm{I}, 92}=0.1 \mathrm{I}\right.$, n.s.; $\mathrm{F}_{(\mathrm{EtOH}) 1,92}=18.5 \mathrm{I}, p<0.00 \mathrm{I} ; \mathrm{F}_{(\mathrm{NAL} \times \mathrm{EtOH}) \mathrm{I}, 92}=0.98$, n.s.) and pouncing $\left((\mathbf{b}) \mathrm{F}_{(\mathrm{NAL}) 1,92}=0.59\right.$, n.s.; $\left.\left.F_{(E t O H) 1,92}=29.64, p<0.001 ; F_{(N A L} \times E t O H\right) 1,92=3.25, p=0.07\right)$ induced by ethanol $\left(E t O H, 0.25 \mathrm{~g} / / \mathrm{kg}\right.$, i.p.). The $C B_{1}$ cannabinoid receptor antagonist SRI4I7I6A (SR, $0.1 \mathrm{mg} / \mathrm{kg}$, i.p.) and the dopamine receptor antagonist $\alpha$-flupenthixol (FLUP, $0.125 \mathrm{mg} / \mathrm{kg}$, i.p.) antagonized the increase in pinning and

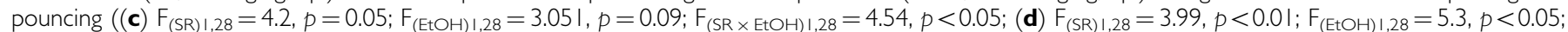

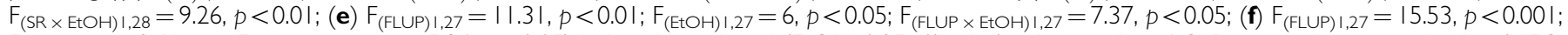

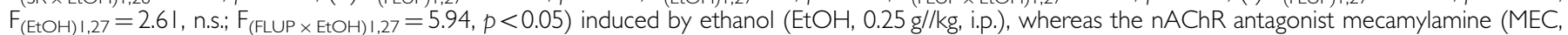

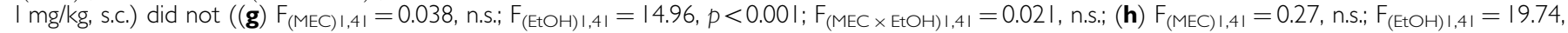

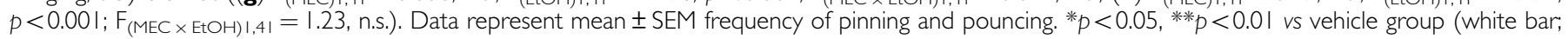
Tukey's post hoc test, $n=8-12$ per treatment group).
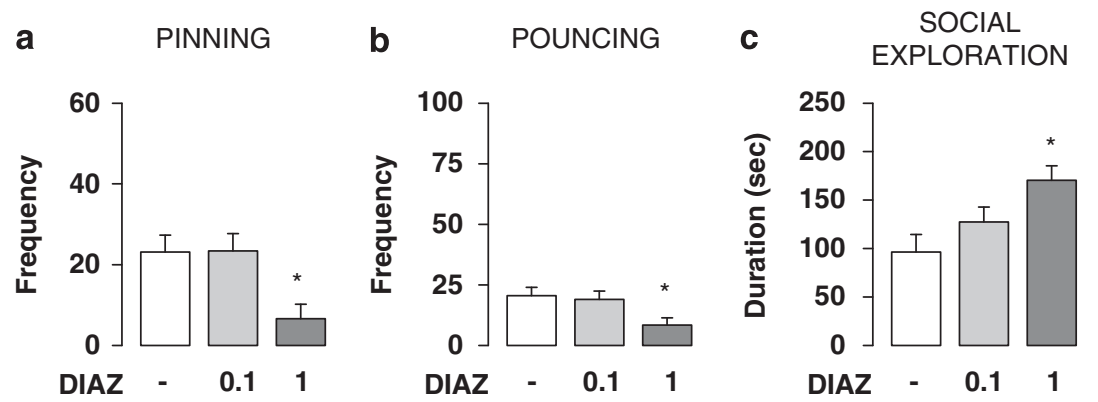

Figure 10 Diazepam (DIAZ, 0.I I I mg/ $/ \mathrm{kg}$, i.p.) decreased pinning $\left((\mathbf{a}) F_{2,23}=5.64, p<0.05\right)$ and pouncing $\left((\mathbf{b}) F_{2,23}=3.96, p<0.05\right)$, but increased social exploration $\left((\mathbf{c}) F_{2,23}=5.22, p<0.05\right)$. Data represent mean \pm SEM frequency of pinning and pouncing and mean \pm SEM duration of social exploration. * $p<0.05$ vs vehicle group (white bar; Tukey's post hoc test, $n=8$ per treatment group).

and ethanol (Van Ree et al, 1999; Di Chiara, 2000; Picciotto and Corrigall, 2002; Weiss and Porrino, 2002; Laviolette and van der Kooy, 2004; Cohen et al, 2005; Maldonado et al, 2006; Pierce and Kumaresan, 2006; Markou, 2008). It is therefore possible that nicotine and ethanol increase social play behavior through interaction with opioid, cannabinoid, and/or dopaminergic neurotransmission. Indeed, the increase in social play induced by nicotine was blocked by pretreatment with the opioid receptor antagonist naloxone, the $\mathrm{CB}_{1}$ cannabinoid receptor antagonist SR141716A, and the dopamine receptor antagonist $\alpha$-flupenthixol. There is overlapping distribution of $n A c h R s, C_{1}$, opioid, and dopamine receptors in brain regions involved in positive emotions and motivation, such as the nucleus accumbens, 

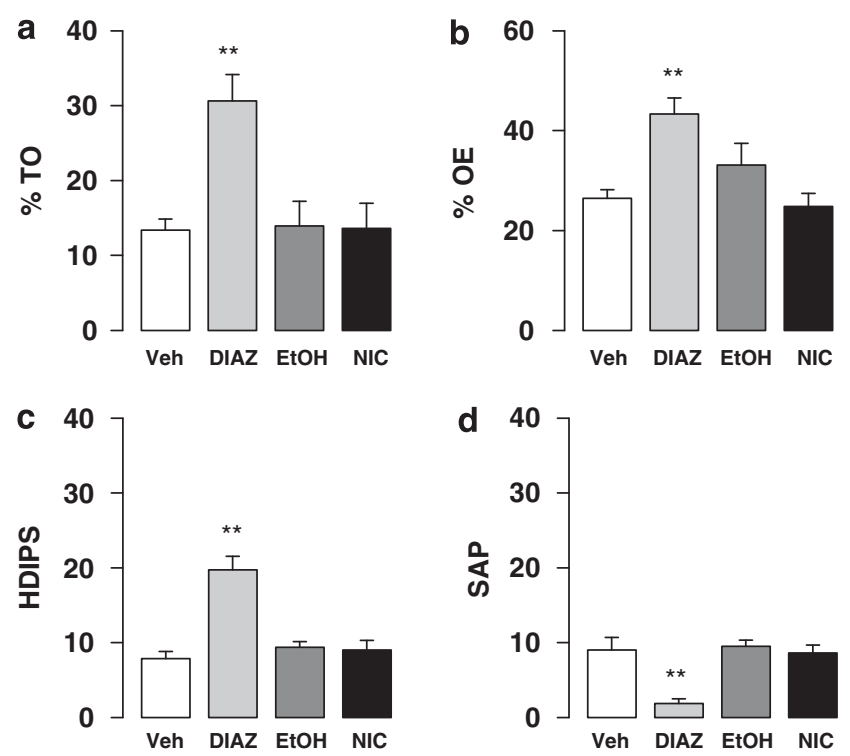

Figure I I Effects of nicotine, ethanol, and diazepam on anxiety-related behaviors in the elevated plus-maze. Diazepam (DIAZ, I mg/kg, i.p.) increased the time spent in the open arms of the maze (\%TO (a) $\left.F_{3,30}=7.56, p<0.00 \mathrm{I}\right)$ and the number of entries into the open arms $\left(\% \mathrm{OE}(\mathbf{b}) \mathrm{F}_{3,30}=6.94, p=0.00 \mathrm{I}\right)$. Moreover, it increased the number of head dips (HDIPS (c) $F_{3,30}=18.94 ; p<0.001$ ) and reduced the frequency of stretched-attend postures (SAP (d) $F_{3,30}=9.07, p<0.00 \mathrm{I}$ ). None of these parameters was affected by nicotine (NIC, $0.1 \mathrm{mg} / \mathrm{kg}$, s.c.) and ethanol $(\mathrm{EtOH}, 0.25 \mathrm{~g} / \mathrm{kg}$, i.p.) exposure. Data represent mean \pm SEM of the percent time spent on the open arms (\% TO), percent of open entries (\% OE), number of head dips (HDIPS) and number of stretched-attend postures (SAP). $* *$ * $p<0.01$ vs vehicle group (white bar; Tukey's post hoc test, $n=7-8$ per treatment group).

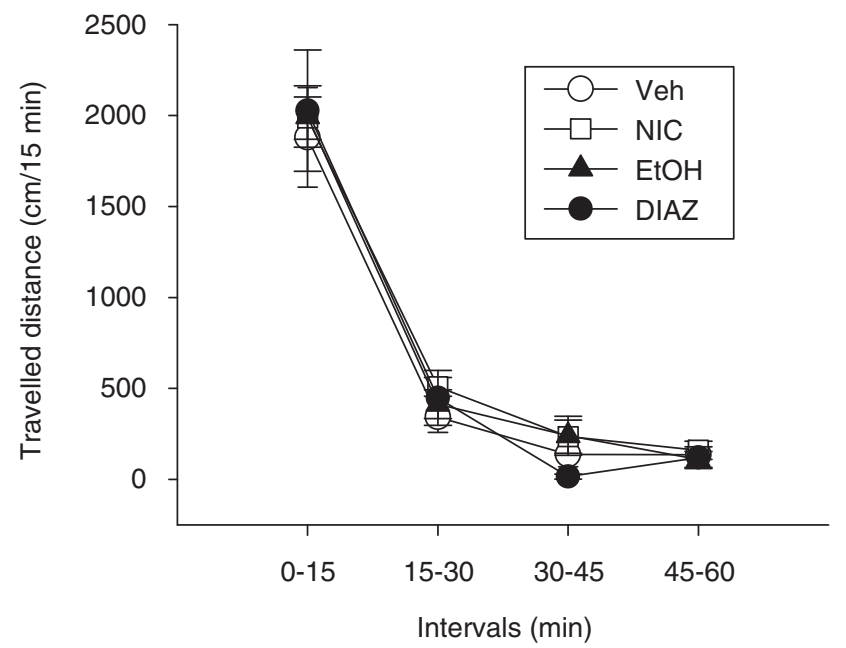

Figure 12 Effects of nicotine, ethanol, and diazepam on locomotor activity. Nicotine (NIC, $0.1 \mathrm{mg} / \mathrm{kg}$, s.c.), ethanol (EtOH, $0.25 \mathrm{~g} / \mathrm{kg}$, i.p.), and diazepam (DIAZ, I mg/kg, i.p.) did not affect locomotor activity during any of the $15 \mathrm{~min}$ intervals of the test $\left(F_{\text {(treatment) } 3,84}=0.31\right.$, n.s.; $F_{\text {(intervals) } 3,84}=176,3, p<0.00 I ; F_{\text {(treatment } \times \text { interval) } 3,84}=0.25$, n.s.).

ventral tegmental area, amygdala, prefrontal and orbitofrontal cortex (Mansour et al, 1994a, b; Tsou et al, 1998; Picciotto et al, 2000). Thus, these data suggest that the increase in social play induced by nicotine is the result of activation of dopaminergic, opioid, and cannabinoid neurotransmission mediated by $\mathrm{nAchR}$ stimulation in these brain regions (Di Chiara and Imperato, 1988; Houdi et al, 1991; Gonzalez et al, 2002; Britt and McGehee, 2008). Clearly, the exact neural sites of action of nicotine, and how stimulation of nAchRs alters dopaminergic, opioid, and cannabinoid neurotransmission to mediate the effects on social play behavior remain to be elucidated.

The increase in social play induced by ethanol was antagonized by the $\mathrm{CB}_{1}$ cannabinoid receptor antagonist SR141716A and the dopamine receptor antagonist $\alpha$-flupenthixol. Like nicotine, ethanol might increase social play by changing endocannabinoid activity in brain areas involved in positive emotions and motivation (eg, Caillé et al, 2007), which, in turn, would lead to activation of dopaminergic neurotransmission, although ethanol could, of course, also enhance social play by direct activation of dopaminergic neurotransmission (Di Chiara and Imperato, 1988; Brodie et al, 1999). Previous studies have shown that nicotine and ethanol interact in the regulation of emotional behavior during adolescence (Abreu-Villaca et al, 2008). However, unlike nicotine, the effects of ethanol on social play were not blocked by the opioid receptor antagonist naloxone, indicating a divergence in the pharmacological mechanisms underlying the effects of nicotine and ethanol on social play. Two further observations support this notion. First, pretreatment with mecamylamine did not counteract the increase in pinning and pouncing induced by ethanol, showing that ethanol does not increase social play by acting through nAchRs. Second, combined treatment with subeffective doses of nicotine and ethanol induced a slight increase in play solicitation, but did not increase pinning. Together, these data therefore suggest that nicotine and ethanol enhance social play behavior through interactions with neurotransmitter systems involved in positive emotions and motivation, but through partially dissociable mechanisms of action.

It was recently reported that naloxone and the selective $\mu$-opioid receptor antagonist CTOP counteracted the stimulating effects of ethanol on social play (Varlinskaya and Spear, 2009). Interestingly, in the study by Varlinskaya and Spear (2009), animals were socially isolated for only $30 \mathrm{~min}$ before the test, and tested against nonisolated, untreated partners, resulting in lower levels of social play than in our setup. Thus, ethanol-induced facilitation of social play under conditions of moderate social motivation, and with test partners that do not reciprocate social initiative to the same degree, is opioiddependent, whereas the enhancement of social play by ethanol when both animals are equally motivated (ie, both treated with ethanol and both isolated for $3.5 \mathrm{~h}$ before testing) is not. Regardless, what these data collectively show is that ethanol-induced enhancement of social interactions has opioid-dependent and opioid-independent components, a suggestion that is supported by the finding of Varlinskaya and Spear (2009) that naloxone and CTOP did not block the ethanol-induced increase in social investigation.

Anxiolytic effects have been suggested to underlie the prosocial properties of ethanol and nicotine (File and Seth, 2003; Cheeta et al, 2001a). Therefore, it is possible that anxiolytic effects contribute to the increase in social play induced by nicotine and ethanol. Our results, however, do not support this possibility. Nicotine increased social play 
to a similar extent in a familiar and an unfamiliar test cage, showing that the effects of this drug on social play behavior do not change in a mildly anxiogenic environment. By and large, ethanol also increased social play in both familiar and unfamiliar environments (see Figures 4, 5, 6, and 9), although in one particular experiment, the effect of ethanol on pouncing was more pronounced in an unfamiliar test cage (Figure 6b). Thus, if anything, anxiolytic effects only play a very minor role in the effect of ethanol on social play in young adolescent rats (Varlinskaya and Spear, 2002, 2006). Furthermore, compared with the prototypical anxiolytic diazepam, doses of nicotine and ethanol that increased social play had no anxiolytic effects in the elevated plusmaze. As expected, adolescent rats treated with diazepam spent more time in the open arms of the maze, exhibited a significantly higher number of head dips and a lower number of stretched-attend postures, which is indicative of anxiolytic-like effects of the drug. None of these parameters was affected by nicotine or ethanol. Interestingly, the anxiolytic dose of diazepam reduced social play behavior in adolescent rats, but increased social exploratory behavior. This experiment was performed in a nonanxiogenic, ie, dimly lit and familiar, environment. In addition, diazepam did not affect locomotor activity. Therefore, we do not think that anxiolytic or sedative properties of diazepam underlie the changes in social interaction. Rather, the effects of diazepam may be the result of behavioral competition, leading to a reorganization of the social repertoire of the animals, whereby playful social behaviors are replaced by exploratory forms of social interaction. These results have important implications. First, they reveal a dissociation between the effects of nicotine and ethanol on social behavior and their anxiolytic-like properties; thus, the prosocial effects of nicotine and ethanol during adolescence are not secondary to anxiolytic effects of these drugs. Second, the present results confirm previous findings showing that anxiolytic and antidepressant drugs do not necessarily increase social play behavior (Vanderschuren et al, 1997; Homberg et al, 2007). Third, the finding that diazepam decreased social play behavior while increasing social exploration confirms that social behaviors related and unrelated to play have different ontogenetic profiles and different neural underpinnings (Vanderschuren et al, 1997).

In summary, these results show that nicotine and ethanol increase social play behavior in adolescent rats, and shed light on the neurobehavioral mechanisms underlying these effects. In particular, the augmenting effects of nicotine and ethanol on social play are behaviorally specific, mediated through neurotransmitter systems involved in positive emotions and motivation, partially divergent on the pharmacological level, and unrelated to anxiety-related behaviors. Given the importance of peer relationships during adolescence, and the high rates of tobacco and alcohol use among teenagers, increasing our knowledge about how these drugs affect social behavior at this age is an important issue in addiction research.

\section{ACKNOWLEDGEMENTS}

This study was supported by National Institute on Drug Abuse Grant R01 DA022628-01 (LJMJV). This research was performed within the framework of project T5-107 of the Dutch Top Institute Pharma. We thank MH Broekhoven and R Damsteegt for practical assistance.

\section{DISCLOSURE/CONFLICT OF INTEREST}

The authors declare that, except for income received from their primary employers, no financial support or compensation has been received from any individual or corporate entity over the past 3 years for research or professional service and there are no personal financial holdings that could be perceived as constituting a potential conflict of interest.

\section{REFERENCES}

Abreu-Villaca Y, Nunes F, do EQ-GF, Manhaes AC, Filgueiras CC (2008). Combined exposure to nicotine and ethanol in adolescent mice differentially affects anxiety levels during exposure, short-term, and long-term withdrawal. Neuropsychopharmacology 33: 599-610.

Berridge KC (2007). The debate over dopamine's role in reward: the case for incentive salience. Psychopharmacology 191: 391-431.

Berridge KC, Kringelbach ML (2008). Affective neuroscience of pleasure: reward in humans and animals. Psychopharmacology 199: 457-480.

Britt JP, McGehee DS (2008). Presynaptic opioid and nicotinic receptor modulation of dopamine overflow in the nucleus accumbens. J Neurosci 28: 1672-1681.

Brodie MS, Pesold C, Appel SB (1999). Ethanol directly excites dopaminergic ventral tegmental area reward neurons. Alcohol Clin Exp Res 23: 1848-1852.

Caillé S, Alvarez-Jaimes L, Polis I, Stouffer DG, Parsons LH (2007). Specific alterations of extracellular endocannabinoid levels in the nucleus accumbens by ethanol, heroin, and cocaine selfadministration. J Neurosci 27: 3695-3702.

Calcagnetti DJ, Schechter MD (1992). Place conditioning reveals the rewarding aspect of social interaction in juvenile rats. Physiol Behav 51: 667-672.

Cardoso RA, Brozowski SJ, Chavez-Noriega LE, Harpold M, Valenzuela CF, Harris RA (1999). Effects of ethanol on recombinant human neuronal nicotinic acetylcholine receptors expressed in Xenopus oocytes. J Pharmacol Exp Ther 289: 774-780.

Cheeta S, Irvine E, File SE (2001a). Social isolation modifies nicotine's effects in animal tests of anxiety. Br J Pharmacol 132: 1389-1395.

Cheeta S, Irvine EE, Tucci S, Sandhu J, File SE (2001b). In adolescence, female rats are more sensitive to the anxiolytic effect of nicotine than are male rats. Neuropsychopharmacology 25: 601-607.

Cohen C, Kodas E, Griebel G (2005). CB1 receptor antagonists for the treatment of nicotine addiction. Pharmacol Biochem Behav 81: 387-395.

Di Chiara G (2000). Role of dopamine in the behavioural actions of nicotine related to addiction. Eur J Pharmacol 393: 295-314.

Di Chiara G, Imperato A (1988). Drugs abused by humans preferentially increase synaptic dopamine concentrations in the mesolimbic system of freely moving rats. Proc Natl Acad Sci USA 85: 5274-5278.

Dopico AM, Lovinger DM (2009). Acute alcohol action and desensitization of ligand-gated ion channels. Pharmacol Rev 61: 98-114.

Douglas LA, Varlinskaya EI, Spear LP (2004). Rewarding properties of social interactions in adolescent and adult male and 
female rats: impact of social versus isolate housing of subjects and partners. Dev Psychobiol 45: 153-162.

Elliott BM, Faraday MM, Phillips JM, Grunberg NE (2004). Effects of nicotine on elevated plus maze and locomotor activity in male and female adolescent and adult rats. Pharmacol Biochem Behav 77: 21-28.

Fagen R (1981). Animal Play Behavior. Oxford University Press: Oxford.

File SE, Seth P (2003). A review of 25 years of the social interaction test. Eur J Pharmacol 463: 35-53.

Gardner EL (2005). Endocannabinoid signaling system and brain reward: emphasis on dopamine. Pharmacol Biochem Behav 81: 263-284.

Gilbert DG, Robinson JH, Chamberlin CL, Spielberger CD (1989). Effects of smoking/nicotine on anxiety, heart rate, and lateralization of EEG during a stressful movie. Psychophysiology 26: 311-320.

Gonzalez S, Cascio MG, Fernandez-Ruiz J, Fezza F, Di Marzo V, Ramos JA (2002). Changes in endocannabinoid contents in the brain of rats chronically exposed to nicotine, ethanol or cocaine. Brain Res 954: 73-81.

Hol T, Van den Berg CL, Van Ree JM, Spruijt BM (1999). Isolation during the play period in infancy decreases adult social interactions in rats. Behav Brain Res 100: 91-97.

Homberg JR, Schiepers OJG, Schoffelmeer ANM, Cuppen E, Vanderschuren LJMJ (2007). Acute and constitutive increases in central serotonin levels reduce social play behaviour in periadolescent rats. Psychopharmacology 195: 175-182.

Houdi AA, Pierzchala K, Marson L, Palkovits M, Van Loon GR (1991). Nicotine-induced alteration in Tyr-Gly-Gly and Metenkephalin in discrete brain nuclei reflects altered enkephalin neuron activity. Peptides 12: 161-166.

Humphreys AP, Einon DF (1981). Play as a reinforcer for mazelearning in juvenile rats. Anim Behav 29: 259-270.

Kushner MG, Abrams K, Borchardt C (2000). The relationship between anxiety disorders and alcohol use disorders: a review of major perspectives and findings. Clin Psychol Rev 20: 149-171.

Kushner MG, Sher KJ, Beitman BD (1990). The relation between alcohol problems and the anxiety disorders. Am J Psychiatry 147: 685-695.

Laviolette SR, van der Kooy D (2004). The neurobiology of nicotine addiction: bridging the gap from molecules to behaviour. Nat Rev Neurosci 5: 55-65.

Maldonado R, Valverde O, Berrendero F (2006). Involvement of the endocannabinoid system in drug addiction. Trends Neurosci 29: 225-232.

Mansour A, Fox CA, Burke S, Meng F, Thompson RC, Akil H et al (1994a). Mu, delta, and kappa opioid receptor mRNA expression in the rat CNS: an in situ hybridization study. J Comp Neurol 350: 412-438.

Mansour A, Fox CA, Thompson RC, Akil H, Watson SJ (1994b). mu-Opioid receptor mRNA expression in the rat CNS: comparison to mu-receptor binding. Brain Res 643: 245-265.

Markou A (2008). Review. Neurobiology of nicotine dependence. Philos Trans R Soc Lond B Biol Sci 363: 3159-3168.

Matta SG, Balfour DJ, Benowitz NL, Boyd RT, Buccafusco JJ, Caggiula AR et al (2007). Guidelines on nicotine dose selection for in vivo research. Psychopharmacology 190: 269-319.

Narahashi T, Aistrup GL, Marszalec W, Nagata K (1999). Neuronal nicotinic acetylcholine receptors: a new target site of ethanol. Neurochem Int 35: 131-141.

Niesink RJ, Van Ree JM (1989). Involvement of opioid and dopaminergic systems in isolation-induced pinning and social grooming of young rats. Neuropharmacology 28: 411-418.

Normansell L, Panksepp J (1990). Effects of morphine and naloxone on play-rewarded spatial discrimination in juvenile rats. Dev Psychobiol 23: 75-83.
Panksepp J, Siviy SM, Normansell L (1984). The psychobiology of play: theoretical and methodological perspectives. Neurosci Biobehav Rev 8: 465-492.

Pellis S, Pellis V (1987). Play-fighting differs from serious fighting in both target of attack and tactics of fighting in the laboratory rat Rattus norvegicus. Aggress Behav 13: 227-242.

Pellis SM, Pellis VC (1990). Differential rates of attack, defense, and counterattack during the developmental decrease in play fighting by male and female rats. Dev Psychobiol 23: 215-231.

Pellis SM, Pellis VC (1991). Attack and defense during play fighting appear to be motivationally independent behaviors in muroid rodents. Psychol Rec 41: 184-191.

Pellow S, File SE (1986). Anxiolytic and anxiogenic drug effects on exploratory activity in an elevated plus-maze: a novel test of anxiety in the rat. Pharmacol Biochem Behav 24: 525-529.

Picciotto MR, Caldarone BJ, King SL, Zachariou V (2000). Nicotinic receptors in the brain. Links between molecular biology and behavior. Neuropsychopharmacology 22: 451-465.

Picciotto MR, Corrigall WA (2002). Neuronal systems underlying behaviors related to nicotine addiction: neural circuits and molecular genetics. J Neurosci 22: 3338-3341.

Pierce RC, Kumaresan V (2006). The mesolimbic dopamine system: the final common pathway for the reinforcing effect of drugs of abuse? Neurosci Biobehav Rev 30: 215-238.

Pomerleau OF (1986). Nicotine as a psychoactive drug: anxiety and pain reduction. Psychopharmacol Bull 22: 865-869.

Pomerleau OF, Pomerleau CS (1990). Behavioural studies in humans: anxiety, stress and smoking. Ciba Found Symp 152: 225-235.

Potegal M, Einon D (1989). Aggressive behaviors in adult rats deprived of playfighting experience as juveniles. Dev Psychobiol 22: 159-172.

Salamone JD, Correa M, Mingote SM, Weber SM (2005). Beyond the reward hypothesis: alternative functions of nucleus accumbens dopamine. Curr Opin Pharmacol 5: 34-41.

Siviy SM, Line BS, Darcy EA (1995). Effects of MK-801 on roughand-tumble play in juvenile rats. Physiol Behav 57: 843-847.

Solinas M, Goldberg SR (2005). Motivational effects of cannabinoids and opioids on food reinforcement depend on simultaneous activation of cannabinoid and opioid systems. Neuropsychopharmacology 30: 2035-2045.

Špinka M, Newberry RC, Bekoff M (2001). Mammalian play: training for the unexpected. Q Rev Biol 76: 141-168.

Tabakoff B, Hoffman PL (1996). Alcohol addiction: an enigma among us. Neuron 16: 909-912.

Thiel KJ, Okun AC, Neisewander JL (2008). Social rewardconditioned place preference: a model revealing an interaction between cocaine and social context rewards in rats. Drug Alcohol Depend 96: 202-212.

Trezza V, Damsteegt R, Vanderschuren LJMJ (2009). Conditioned place preference induced by social play behavior: parametrics, extinction, reinstatement and disruption by methylphenidate. Eur Neuropsychopharmacol 19: 659-669.

Trezza V, Vanderschuren LJMJ (2008a). Cannabinoid and opioid modulation of social play behavior in adolescent rats: differential behavioral mechanisms. Eur Neuropsychopharmacol 18: 519-530.

Trezza V, Vanderschuren LJMJ (2008b). Bidirectional cannabinoid modulation of social behavior in adolescent rats. Psychopharmacology 197: 217-227.

Trezza V, Vanderschuren LJMJ (2009). Divergent effects of anandamide transporter inhibitors with different target selectivity on social play behavior in adolescent rats. J Pharmacol Exp Ther 328: 343-350.

Tsou K, Brown S, Sanudo-Pena MC, Mackie K, Walker JM (1998). Immunohistochemical distribution of cannabinoid CB1 receptors in the rat central nervous system. Neuroscience 83: 393-411. 
van den Berg CL, Hol T, Van Ree JM, Spruijt BM, Everts H, Koolhaas JM (1999a). Play is indispensable for an adequate development of coping with social challenges in the rat. Dev Psychobiol 34: 129-138.

van den Berg CL, Pijlman FT, Koning HA, Diergaarde L, Van Ree JM, Spruijt BM (1999b). Isolation changes the incentive value of sucrose and social behaviour in juvenile and adult rats. Behav Brain Res 106: 133-142.

van Ree JM, Gerrits MAFM, Vanderschuren LJMJ (1999). Opioids, reward and addiction: an encounter of biology, psychology, and medicine. Pharmacol Rev 51: 341-396.

Vanderschuren LJMJ, Niesink RJM, Spruijt BM, Van Ree JM (1995a). Influence of environmental factors on social play behavior of juvenile rats. Physiol Behav 58: 119-123.

Vanderschuren LJMJ, Niesink RJM, Spruijt BM, Van Ree JM (1995b). Effects of morphine on different aspects of social play in juvenile rats. Psychopharmacology 117: 225-231.

Vanderschuren LJMJ, Niesink RJM, Van Ree JM (1997). The neurobiology of social play behavior in rats. Neurosci Biobehav Rev 21: 309-326.
Vanderschuren LJMJ, Trezza V, Griffioen-Roose S, Schiepers OJG, Van Leeuwen N, De Vries TJ et al (2008). Methylphenidate disrupts social play behavior in adolescent rats. Neuropsychopharmacology 33: 2946-2956.

Varlinskaya EI, Spear LP (2002). Acute effects of ethanol on social behavior of adolescent and adult rats: role of familiarity of the test situation. Alcohol Clin Exp Res 26: 1502-1511.

Varlinskaya EI, Spear LP (2006). Differences in the social consequences of ethanol emerge during the course of adolescence in rats: social facilitation, social inhibition, and anxiolysis. Dev Psychobiol 48: 146-161.

Varlinskaya EI, Spear LP (2009). Ethanol-Induced social facilitation in adolescent rats: role of endogenous activity at mu opioid receptors. Alcohol Clin Exp Res 33: 991-1000.

Varlinskaya EI, Spear LP, Spear NE (2001). Acute effects of ethanol on behavior of adolescent rats: role of social context. Alcohol Clin Exp Res 25: 377-385.

Weiss F, Porrino LJ (2002). Behavioral neurobiology of alcohol addiction: recent advances and challenges. J Neurosci 22: 3332-3337. 